\title{
Alpha2A-Adrenoceptors are Important Modulators of the Effects of D-Amphetamine on Startle Reactivity and Brain Monoamines
}

\author{
Janne Lähdesmäki*,', Jukka Sallinen², Ewen MacDonald ${ }^{\mathbf{3}}$ and Mika Scheinin' \\ 'Department of Pharmacology and Clinical Pharmacology, University of Turku, Turku, Finland; ${ }^{2}$ Drug Discovery and Pharmacology, Orion \\ Corporation, Orion Pharma, Turku, Finland; ${ }^{3}$ Department of Pharmacology and Toxicology, University of Kuopio, Kuopio, Finland
}

\begin{abstract}
Amphetamines are commonly used to treat attention-deficit hyperactivity disorder, but are also widely abused. They are employed in schizophrenia-related animal models as they disrupt the prepulse inhibition (PPI) of the acoustic startle response. The behavioral effects of amphetamines have mainly been attributed to changes in dopamine transmission, but they also involve increases in the synaptic concentrations of norepinephrine (NE). $\alpha_{2}$-Adrenoceptors $\left(\alpha_{2}\right.$-ARs) regulate the excitability and transmitter release of brain monoaminergic neurons mainly as inhibitory presynaptic auto- and heteroreceptors. Modulation of acoustic startle and its PPI by the $\alpha_{2 A^{-}}$ AR subtype was investigated with mice lacking the $\alpha_{2 A}-A R\left(\alpha_{2 A}-K O\right)$ and their wild-type (WT) controls, without drugs and after administration of the $\alpha_{2}$-AR agonist dexmedetomidine or the antagonist atipamezole. The interaction of D-amphetamine (D-amph) and the $\alpha_{2}$-AR-noradrenergic neuronal system in modulating startle reactivity and in regulating brain monoamine metabolism was assessed as the behavioral and neurochemical responses to D-amph alone, or to the combination of D-amph and dexmedetomidine or atipamezole. $\alpha_{2 A}-K O$ mice were supersensitive to both neurochemical and behavioral effects of D-amph. Brain NE stores of $\alpha_{2 A}-K O$ mice were depleted by D-amph, revealing the $\alpha_{2 A}$-AR as essential in modulating the actions of D-amph. Also, increased startle responses and more pronounced disruption of PPI were noted in D-amph-treated $\alpha_{2 A}-K O$ mice. $\alpha_{2 A}-A R$ also appeared to be responsible for the startlemodulating effects of $\alpha_{2}$-AR drugs, since the startle attenuation after the $\alpha_{2}$-AR agonist dexmedetomidine was absent in $\alpha_{2 A}-K O$ mice, and the $\alpha_{2}-A R$ antagonist atipamezole had opposite effects on the startle reflex in $\alpha_{2 A}-K O$ and WT mice.

Neuropsychopharmacology (2004) 29, 1282-1293, advance online publication, 24 March 2004; doi:I0. I038/sj.npp. I 300428
\end{abstract}

Keywords: receptors, adrenergic, alpha-2; norepinephrine; startle reaction; sensorimotor gating; dextroamphetamine; mice, genetically modified

\section{INTRODUCTION}

Amphetamine-like psychostimulants are the best-documented pharmacotherapy for attention-deficit hyperactivity disorder (ADHD) (Arnold et al, 1976; Wilens et al, 1995; Spencer et al, 1996). Amphetamines are also powerful reinforcing drugs, primarily due to their capacity to activate the mesocorticolimbic dopamine (DA) system (Wise, 1996). They are therefore widely abused, with repeated administration increasing susceptibility to drug-induced psychosis (Ujike, 2002). D-Amphetamine (D-Amph) acts by inhibiting neuronal reuptake and by facilitating release of $\mathrm{DA}$,

*Correspondence: Dr J Lähdesmäki, Department of Pharmacology and Clinical Pharmacology, University of Turku, Itäinen Pitkäkatu 4, FIN20520 Turku, Finland, Tel: + 3582 3338585, Fax: + 35823337216 , E-mail: janne.lahdesmaki@utu.fi

Received 29 October 2003; revised 27 January 2004; accepted 29 January 2004

Online publication: 6 February 2004 at http://www.acnp.org/citations/ Npp02060403498/default.pdf norepinephrine (NE), and serotonin (5-HT). In addition to the established role of DA, there is emerging evidence that also NE contributes to the behavioral effects of D-Amph either through modulation of DA transmission or through independent mechanisms (Segal and Kuczenski, 1994; Xu et al, 2000; Weinshenker et al, 2002).

Activation of presynaptic and somatodendritic $\alpha_{2}$-adrenoceptors $\left(\alpha_{2}\right.$-ARs) inhibits $\mathrm{NE}$ release and firing of noradrenergic neurons. The $\alpha_{2 \mathrm{~A}}$-AR subtype mainly contributes to the inhibition of both neuronal excitability and $\mathrm{NE}$ release; the $\alpha_{2 \mathrm{C}}-\mathrm{AR}$ has a similar, but lesser role (Lakhlani et al, 1997; Starke, 2001). Moreover, the $\alpha_{2 \mathrm{~A}}$-AR and to a minor extent the $\alpha_{2 \mathrm{C}}$-AR modulate the neurotransmitter release of brain dopaminergic and serotonergic neurons (Yavich et al, 1997; Scheibner et al, 2001). In rat frontal cortex, the increased NE release following systemic administration of D-amph has been shown to be augmented under blockade of all $\alpha_{2}$-AR subtypes with subtype nonselective antagonists (Wortley et al, 1999; Geranton et al, 2003). In addition, recent evidence from microdialysis 
studies in rats suggests that there are regional differences in the NE-modulating effects of locally administered $\mathrm{D}$-Amph in the CNS (Geranton et al, 2003). In the hypothalamus, there was a stronger increase in D-Amphinduced $\mathrm{NE}$ efflux in comparison to the frontal cortex; pretreatment with atipamezole, an $\alpha_{2}$-AR antagonist, abolished this difference by augmenting NE release in the frontal cortex, but not in the hypothalamus (Geranton et al, 2003). Thus, it seems that the NE turnover in the frontal cortex is under stronger inhibitory $\alpha_{2}$-autoreceptor control than that in the hypothalamus. Interestingly, the $\alpha_{2 \mathrm{~A}}$-ARs in mouse frontal cortex were also reported to mediate the beneficial effects of cognitiveenhancing effects of guanfacine, an $\alpha_{2}$-AR agonist clinically employed in the treatment of ADHD (Franowicz et al, 2002). Still, the extent to which $\alpha_{2}$-ARs contribute to modulating the neurochemical and behavioral response to D-Amph-like psychostimulants is not thoroughly understood.

The startle reflex, a fast twitch of the body musculature by a sudden and intense tactile, visual, or acoustic stimulus, is usually classified as a defensive response. The startle reflex is an important behavioral tool to assess the mechanisms of sensorimotor response plasticity. By modulating the experimental settings, the startle reflex can be used, for example, as a model to investigate the neurobiology of anxiety and fear. Prepulse inhibition (PPI) of the startle response is a cross-species measure of sensorimotor gating. In PPI, the startle magnitude is reduced when the startle stimulus is preceded by a low-intensity prepulse (Koch, 1999; Swerdlow et al, 2000). In humans, disruption of PPI has been reported in schizophrenia (Braff et al, 2001) and ADHD (Hawk et al, 2003). In rodents, D-amph is used to pharmacologically disrupt PPI (Mansbach et al, 1988; Ralph et al, 2001). Druginduced PPI disruptions are restored by antipsychotic compounds, and because of its predictive validity, the PPI model is used in antipsychotic drug development (Swerdlow et al, 2000).

The $\alpha_{2}$-AR agonist clonidine attenuates (Kumari et al, 1996) and the antagonist yohimbine enhances (Morgan et al, 1993) the startle response in humans, but the receptor subtype(s) mediating these effects is unclear. $\alpha_{2}$-ARdependent modulation of PPI has also been reported. In mice, inactivation of the $\alpha_{2 \mathrm{C}}$-AR gene resulted in increased startle and decreased PPI, whereas $\alpha_{2 \mathrm{C}}$-AR overexpression increased the PPI (Sallinen et al, 1998). Here we examined the startle response and its PPI in mice lacking the gene encoding the $\alpha_{2 \mathrm{~A}}$-AR $\left(\alpha_{2 \mathrm{~A}}\right.$-knockout, $\left.\alpha_{2 \mathrm{~A}}-\mathrm{KO}\right)$ (Altman et al, 1999). Previous studies have linked genetic $\alpha_{2 \mathrm{~A}}$-AR inactivation to impaired function of the prefrontal cortex (Franowicz et al, 2002) and to increased brain NE turnover (Lähdesmäki et al, 2002).

Since D-amph affects NE release and uptake, and because noradrenergic neurotransmission and NE metabolism in the CNS are regulated by $\alpha_{2}$-ARs, D-amph was given alone, and in combination with the $\alpha_{2}$-AR agonist dexmedetomidine or the antagonist atipamezole. In addition to startle reactivity and PPI, the neurochemical effects of D-amph were monitored by measuring the content of NE, DA, 5-HT, and their metabolites in several monoaminergic brain regions.

\section{MATERIALS AND METHODS}

\section{Experimental Animals}

A total of 119 female and 104 male mice of 20-35 weeks of age, weighing $21-32 \mathrm{~g}$ (females) or 26-36 g (males), were used. The generation of a mouse strain with targeted inactivation of the gene for the $\alpha_{2 \mathrm{~A}}$-adrenergic receptor has been described previously (Altman et al, 1999). Heterozygous $\alpha_{2 \mathrm{~A}}$-KO mice were bred to wild-type $\mathrm{C} 57 \mathrm{Bl} / 6 \mathrm{~J}$ for five successive generations to produce a strain of mice with a uniform, predominantly $\mathrm{C} 57 \mathrm{Bl} / 6 \mathrm{~J}$ genetic background. Agematched wild-type C57Bl/6J (WT) mice of the same genetic background (Jackson Laboratories, Bar Harbor, ME, USA) were used as control animals. All efforts were made to minimize animal suffering and the number of animals used. The experiments conformed to the International Council for Laboratory Animal Science (ICLAS) guidelines, and the study had approval of the local committee for laboratory animal welfare. The mice were housed under standard laboratory conditions with a $12: 12$-h light/dark cycle (lights on at 0600 and off at 1800). Experiments were conducted between 0800 and $1630 \mathrm{~h}$. In startle experiments, each animal was tested in three or four startle sessions. Animals used in the analysis of brain monoamines were used solely in this experiment.

\section{Drugs}

Dexmedetomidine hydrochloride (Dex; Orion Corporation, Orion Pharma, Turku, Finland) and atipamezole hydrochloride (Ati; Orion Pharma) were injected subcutaneously (s.c.). D-amph sulfate (D-amph; Sigma, St Louis, MO) was administered intraperitoneally (i.p.). All drugs were dissolved in distilled water, and the injection volume was either $5 \mathrm{ml} / \mathrm{kg}$ (s.c.) or $10 \mathrm{ml} / \mathrm{kg}$ (i.p.).

\section{Startle Apparatus}

Startle experiments were performed in two identical ventilated and illuminated startle chambers $\left(39 \times 38 \times 58 \mathrm{~cm}^{3}\right.$ (length $\times$ width $\times$ height) $)$ (SR-LAB system, San Diego Instruments, San Diego, CA). The chambers consisted of a nonrestrictive Plexiglas cylinder $(3.9 \mathrm{~cm}$ in diameter) resting on a Plexiglas platform. Piezoelectric accelerometers mounted under the cylinders detected and transduced the animal movements. High-frequency speakers (Radio Shack Supertweeter, San Diego, CA), mounted $25 \mathrm{~cm}$ above the cylinder, provided all acoustic stimuli. Presentation of the acoustic stimuli and the piezoelectric responses from the accelerometer were controlled and digitized by the SR-LAB software and interface system. The sensitivity of the chambers was adjusted at average readings of 1000 using the standardization unit from San Diego Instruments. Sound levels within each chamber were measured repeatedly using the A weighing scale (Radio Shack Sound Level Meter, Fort Worth, TX) and were found to remain constant.

\section{Startle Experiments}

Groups of female $\alpha_{2 \mathrm{~A}}$-KO $(n=60)$ and female WT $(n=59)$ mice underwent four separate 13-min startle sessions, with 
a minimum session interval of 12 days. Prior to startle and PPI measurements, they were treated as follows:

Experiment 1: Startle responses and PPI of $30 \alpha_{2 \mathrm{~A}}-\mathrm{KO}$ and 30 WT mice were evaluated at baseline without treatments. No injections were given in this experiment.

Experiments 2 and 3: $60 \alpha_{2 \mathrm{~A}}-\mathrm{KO}$ and 59 WT mice were divided randomly into four groups to receive the subtypenonselective $\alpha_{2}$-antagonist atipamezole $(0.3,1$ or $3 \mathrm{mg} / \mathrm{kg})$ (experiment 2 ) or the agonist dexmedetomidine (10 or $30 \mu \mathrm{g} / \mathrm{kg}$ ) (experiment 3) or vehicle $20 \mathrm{~min}$ before the start of the startle session.

Experiment 4: In the final startle session, the effects of high-dose D-amph $(10 \mathrm{mg} / \mathrm{kg})$ were explored. Vehicle, Ati $1 \mathrm{mg} / \mathrm{kg}$, or Dex $3 \mu \mathrm{g} / \mathrm{kg}$ were injected $20 \mathrm{~min}$, and D-amph $10 \mathrm{~min}$ before the test session.

\section{Design of Startle Sessions}

The following session protocol was employed in all experiments: After a 3-min habituation period, the mice were first exposed to 10 PULSE ALONE trials (block 1); then, in a pseudorandom order to 13 PULSE ALONE trials and three types of PREPULSE + PULSE trials, each consisting of eight trials (block 2); and finally, the mice were again exposed to five PULSE ALONE trials (block 3 ). The duration of a startle session was $13 \mathrm{~min}$. There was an average of $10 \mathrm{~s}$ interval (range, 5-30 s) between trials.

A PULSE ALONE trial consisted of a $40-\mathrm{ms}$ broadband $120 \mathrm{~dB}$ burst. In PREPULSE + PULSE trials, a $40 \mathrm{~ms}$ long 3, 6 or $15 \mathrm{~dB}$ stimulus above the $72 \mathrm{~dB}$ background preceded the $120 \mathrm{~dB}$ pulse by $100 \mathrm{~ms}$. The startle amplitudes from PULSE ALONE and PREPULSE + PULSE trials were determined by averaging 100 readings of $1 \mathrm{~ms}$, each taken from the beginning of the PULSE stimulus onset.

\section{Analysis of Brain Monoamines and Their Metabolites}

Male $\alpha_{2 \mathrm{~A}}$-KO $(n=52)$ and WT $(n=52)$ mice were randomly divided into six groups and received two drug injections 50 and $40 \mathrm{~min}$ before decapitation. The first drug injection (referred here as 'Drug') was either vehicle, Dex $(3 \mu \mathrm{g} / \mathrm{kg})$ or Ati $(1 \mathrm{mg} / \mathrm{kg})$; the second drug injection (referred here as 'Amph') was either vehicle or D-amph $(10 \mathrm{mg} / \mathrm{kg})$. Treatments were vehicle + vehicle, vehicle $+\mathrm{D}$-amph, Dex + D-amph, Ati + D-amph, Dex + vehicle, and Ati + vehicle. Core body temperatures were measured before the first injection and just prior to decapitation, using a rectal probe and a digital thermometer (Ellab, Roedovre, Denmark). After decapitation, the brains were rapidly removed. The cerebral cortex, hippocampus, striatum and the thalamus, and hypothalamus were dissected and placed in preweighed tubes on dry ice.

Biogenic amines (NE, DA, 5-HT), the 5-HT precursor tryptophan (TRP), and the monoamine metabolites were determined from brain homogenates in $0.1 \mathrm{M}$ perchloric acid using electrochemical detection (ESA Coulochem 5011, Bedford, MA) after separation by HPLC on a reversed-phase C18 column (Ultrasphere ODS, $4.6 \times 250 \mathrm{~mm}$, Beckman Instruments, Fullerton, CA). The buffer systems described by Mefford (1981) were used, with the minor modifications described elsewhere (MacDonald et al, 1988).

\section{Data Analysis}

Statistical analyses were conducted using SPSS for Windows release 11.0. (SPSS Inc., Chicago, IL). Genotype comparisons between nontreated or vehicle-treated $\alpha_{2 \mathrm{~A}}-\mathrm{KO}$ and WT mice were performed using independent samples $t$-tests. Results from brain biogenic amine determinations were analyzed using three-way analysis of variance (ANOVA) with genotype $\left(\alpha_{2 \mathrm{~A}}-\mathrm{KO} / \mathrm{WT}\right)$, amph (vehicle/D-amph), and drug (vehicle/Dex/Ati) as factors. For brevity, the main effects of drug and the amph $\times$ drug interaction are not presented. A more comprehensive analysis of the effects of Dex and Ati on the levels of brain monoamine neurotransmitters in $\alpha_{2 \mathrm{~A}}-\mathrm{KO}$ and WT mice has also been reported previously (Lähdesmäki et al, 2003). Within genotypes, contrasts were used in the general linear models as post hoc tests for the differences between treatments.

The extent of PPI was determined as PPI\%, according to the formula $\{100-[$ (mean startle amplitude of PREPULSE + PULSE-trials)/(mean startle amplitude of PULSE ALONE-trials $) \times 100]\}$. Averaged PULSE ALONE trials across blocks 1-3 were used in the calculation of PPI. Startle responses were analyzed from averaged block 1 PULSE ALONE trials to evaluate the potential genotype differences and drug effects on startle reactivity, while avoiding the confounding effect of habituation (Dulawa et al, 2000).

Startle reactivity in experiments 2 and 3 was analyzed using two-way ANOVA, with genotype and drug as factors. A three-way ANOVA, employed similarly as in the analysis of the results of brain biogenic monoamine determinations, was used to analyze startle reactivity and PPI from experiment 4 . Since the ANOVA assessing PPI yielded no interaction including all factors in experiment 4 , the data were collapsed across prepulse intensities to reduce the number of post hoc tests required. To analyze genotype differences in PPI, results from all nontreated (experiment 1) and vehicle-treated (control groups from experiments 2, 3, and 4) mice were pooled and analyzed using repeated-measures ANOVA. Independent samples $t$ tests were used at each prepulse intensity for comparison. Two-way ANOVA for repeated measures was employed to calculate PPI from experiments 2 and 3. Habituation of the startle reflex was calculated as a decrease in startle responses across blocks $1-3$ and analyzed with repeatedmeasures ANOVA. A three-way ANOVA was also used to analyze data from body temperature measurements. ANOVAs were followed by LSD post hoc tests, where applicable. Alpha was set at 0.05 .

\section{RESULTS}

Startle Experiment 1. Baseline Differences of Startle Responses and PPI, and Habituation of the Startle Reflex in Mice with Altered $\alpha_{2 \mathrm{~A}}$-AR Expression

Lack of $\alpha_{2 \mathrm{~A}}$-AR was associated with changes in PPI and startle reactivity at baseline, without drug challenge. Prepulses inhibited startle responses more efficiently in $\alpha_{2 \mathrm{~A}}-\mathrm{KO}$ mice in comparison with WT animals $\left(\mathrm{PPI} \times\right.$ genotype interaction: $\left.\mathrm{F}_{(2,147)}=3.57 ; \quad p=0.031\right)$ (Figure 1). At the highest prepulse intensity, $15 \mathrm{~dB}$, the 

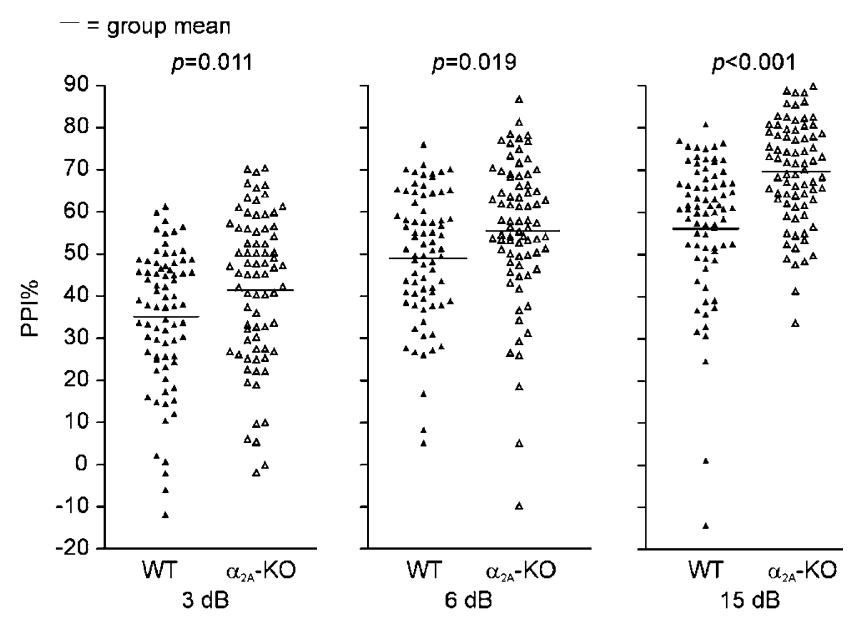

Figure I Baseline PPI (individual means) of nontreated or vehicletreated $\alpha_{2 \mathrm{~A}}-\mathrm{KO}$ (open triangles) and $\mathrm{WT}$ (closed triangles) mice from all experiments (Exp I-4) ( $n=75 /$ group). The PPI values of $\alpha_{2 A}-K O$ mice were consistently greater at all prepulse intensities $(3,6$, and $15 \mathrm{~dB})$ as compared to WT control mice (independent samples t-test). Horizontal lines represent the group means.

$\alpha_{2 \mathrm{~A}}-\mathrm{KO}$ mice had $13 \%$ higher PPI levels than WT mice (mean \pm SEM PPI\%; $57 \pm 2$ and $70 \pm 1$ for WT and $\alpha_{2 \mathrm{~A}}-\mathrm{KO}$ mice; $t=5.15 ; p<0.001)$. The $\alpha_{2 \mathrm{~A}}-\mathrm{KO}$ and $\mathrm{WT}$ mice had similar startle amplitudes to PULSE ALONE stimuli in the first startle experiment, where no injections were given. Vehicle injections in the second startle experiment increased the startle responses of $\alpha_{2 \mathrm{~A}}$-KO mice (mean increase $54 \%$ compared to experiment 1 ), whereas only a minor, nonsignificant increase (8.6\%) was observed in WT mice $(t=2.67 ; p=0.012$ for genotype difference in experiment 2$)$ (Figure 2). The difference in startle reactions between the genotypes induced by the first vehicle injection was attenuated in the third experiment and completely abolished in the fourth experiment. As expected, habituation of the startle reflex was observed in all experiments in both genotypes, as revealed by the significant main effects of block on startle reactivity. The values (mean \pm SEM, arbitrary units) for the startle reactions across blocks 1-3 in experiment 1 were $72 \pm 7,66 \pm 6$, and $55 \pm 5$ for $\alpha_{2 \mathrm{~A}}-\mathrm{KO}$ and $66 \pm 8,60 \pm 6$, and $56 \pm 5$ for $\mathrm{W}$ T animals. There were no interactions between the effects of block and genotype, suggesting that the $\alpha_{2 \mathrm{~A}}-\mathrm{KO}$ mice had normal startle habituation.

\section{Startle Experiments 2 and 3: Effects of Atipamezole and Dexmedetomidine}

Effects of both Ati and Dex were dissimilar between the $\alpha_{2 \mathrm{~A}^{-}}$ $\mathrm{KO}$ and WT mice. A significant genotype $\times$ dose interaction was observed in startle amplitudes after treatment with Ati $\left(\mathrm{F}_{(3,111)}=2.74 ; p=0.044\right)$ (Figure 3a). In response to the subtype nonselective $\alpha_{2}$-antagonist, the startle amplitudes of $\alpha_{2 \mathrm{~A}}-\mathrm{KO}$ mice decreased from $110 \pm 12$ (control) (arbitrary units; mean \pm SEM) to $79 \pm 12(3 \mathrm{mg} / \mathrm{kg})$, whereas an opposite trend (increase) was observed in WT mice, ranging from $72 \pm 8$ to $101 \pm 11$. Dex attenuated startle amplitudes dose-dependently in WT mice, but had no effect on startle responses of $\alpha_{2 \mathrm{~A}}-\mathrm{KO}$ animals $\left(\mathrm{F}_{(3,111)}=3.14 ; p=0.028\right.$ for genotype $\times$ dose interaction) (Figure $3 \mathrm{~b}$ ). The inhibition of

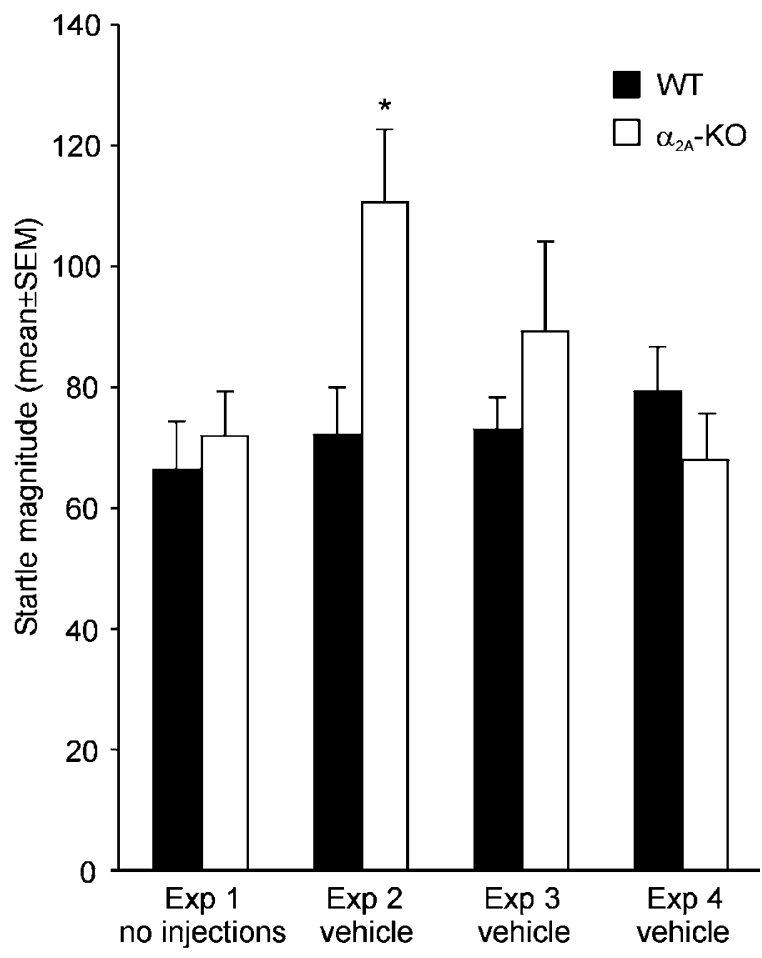

Figure 2 Startle responses of nontreated or vehicle-treated $\alpha_{2 A}-K O$ (open bars) and WT (closed bars) mice in each experiment (Exp I-4). The values are mean startle amplitudes (arbitrary units) \pm SEM $(n=15-30 /$ group). The first vehicle injection given in experiment 2 increased the startle reactivity of $\alpha_{2 \mathrm{~A}}-\mathrm{KO}$ mice compared to control animals ${ }^{*} p=0.012$; independent samples $t$-test). No differences were observed in subsequent experiments.

startle responses in WT mice was significant even after the smallest dose $(3 \mu \mathrm{g} / \mathrm{kg})$ of Dex $(p<0.001)$.

The difference in PPI, observed at baseline between the two genotypes, remained after Ati 0.3 and $1 \mathrm{mg} / \mathrm{kg}$ (Figure 4a) and Dex $3 \mu \mathrm{g} / \mathrm{kg}$ (Figure $4 \mathrm{~b}$ ), with the $\alpha_{2 \mathrm{~A}}-\mathrm{KO}$ mice having slightly higher PPI levels. Dex did not modulate PPI in $\alpha_{2 \mathrm{~A}}-\mathrm{KO}$ mice. The PPI of WT mice was markedly attenuated after Dex 10 and $30 \mu \mathrm{g} / \mathrm{kg}$, but not after $3 \mu \mathrm{g} / \mathrm{kg}$. However, since these doses cause sedation in normal mice, evidenced here as almost nonexistent startle responses of WT mice (Figure 3b), the relevance of the PPI results after the two highest doses of Dex in WT mice is questionable.

\section{Startle Experiment 4. Effects of D-amph on Startle Responses and PPI, and Modulation of D-amph Responses by Subtype Nonselective $\alpha_{2}$-AR Drugs}

In startle amplitudes, there were highly significant genotype $\times$ amph $\left(\mathrm{F}_{(1,111)}=13.3 ; p<0.001\right)$ and genotype $\times$ drug $\left(\mathrm{F}_{(2,111)}=8.28 ; p<0.001\right)$ interactions, indicating a genotype difference in the response to D-amph alone and in the modulation of D-amph responses by Ati and/or Dex (Figure 5a). D-amph increased startle responses of $\alpha_{2 \mathrm{~A}}$-KO mice by $80 \%\left(\mathrm{~F}_{(1,56)}=9.90 ; p=0.003\right)$ compared to vehicletreated controls, but in WT mice the mean startle responses tended to be decreased $(-27 \%)$ after D-amph. Ati did not alter the effect of D-amph on startle responses of $\alpha_{2 \mathrm{~A}}$-KO mice, but in WT mice treated with Ati $+\mathrm{D}$-amph the response was increased to the level of $\alpha_{2 \mathrm{~A}}$-KO mice after 

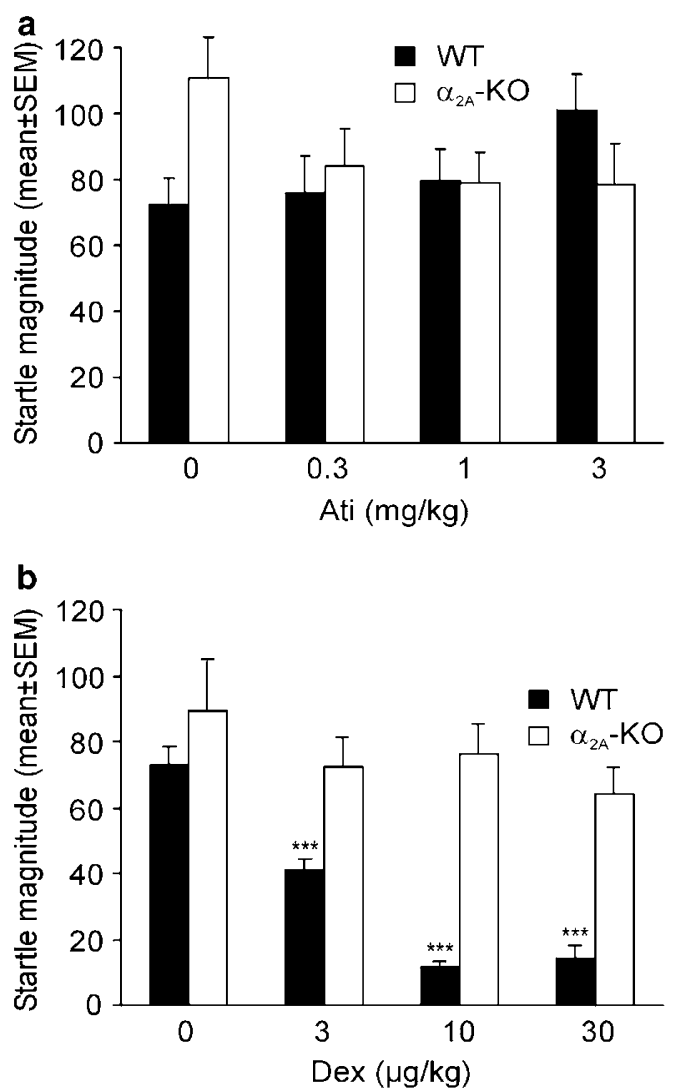

Figure 3 Startle responses of $\alpha_{2 A}-K O$ (open bars) and WT (closed bars) mice (mean \pm SEM, $n=\mid 4-15 /$ group). (a) Atipamezole had opposite effects on the startle reactivity of $\alpha_{2 \mathrm{~A}}-\mathrm{KO}$ and WT control mice, as revealed by significant genotype $\times$ amph interaction in two-way ANOVA $(p=0.044)$. (b) Dexmedetomidine dose-dependently decreased the startle reactions of WT mice, but had no effect in $\alpha_{2 A}-K O$ animals $\left(p=0.028\right.$ for genotype $\times$ dose interaction). ${ }^{*} * * * 0.00$ I in comparison to the vehicle control group.

D-amph alone $\left(\mathrm{F}_{(1,55)}=24.2 ; p<0.001\right)$. Small doses of Dex $(3 \mu \mathrm{g} / \mathrm{kg})$ did not modify the effects of D-amph on startle responses, neither in $\alpha_{2 \mathrm{~A}}$-KO nor in WT mice.

Significant genotype $\times$ amph $\quad\left(\mathrm{F}_{(1,111)}=6.19 ; p=0.014\right)$ and genotype $\times$ drug $\left(\mathrm{F}_{(2,111)}=4.49 ; p=0.013\right)$ interactions were observed also in PPI (Figure $5 \mathrm{~b}$ ). The \% PPI decreased from $51 \pm 2.4$ (vehicle-treated, mean \pm SEM) to $40 \pm 3.3$ (vehicle-D-amph treated) in WT mice $(p=0.016)$ after $\mathrm{D}$-amph. In $\alpha_{2 \mathrm{~A}}-\mathrm{KO}$ mice, the $\mathrm{D}$-amph alone treatment caused a more pronounced decrease in \% PPI from $57 \pm 2.9$ (vehicle treated, mean \pm SEM) to $30 \pm 0.8$ (vehicle-D-amph treated) $(p<0.001)$. Dex partially restored the D-amphdisrupted PPI of $\alpha_{2 \mathrm{~A}}$-KO mice (Figure 5b) ( $p=0.003$ for the difference between vehicle-amph- and Dex-amph-treated $\alpha_{2 \mathrm{~A}}-\mathrm{KO}$ mice), but it had no effect in WT mice. Ati did not modulate the effects of D-amph on PPI.

Effects of D-amph on Brain Biogenic Amines and Their Metabolites, and Modulation of D-amph Responses by Subtype Nonselective $\alpha_{2}$-AR Drugs

$N E$ and $M H P G$. Statistically significant main effects of genotype and amph were noted in almost all studied brain
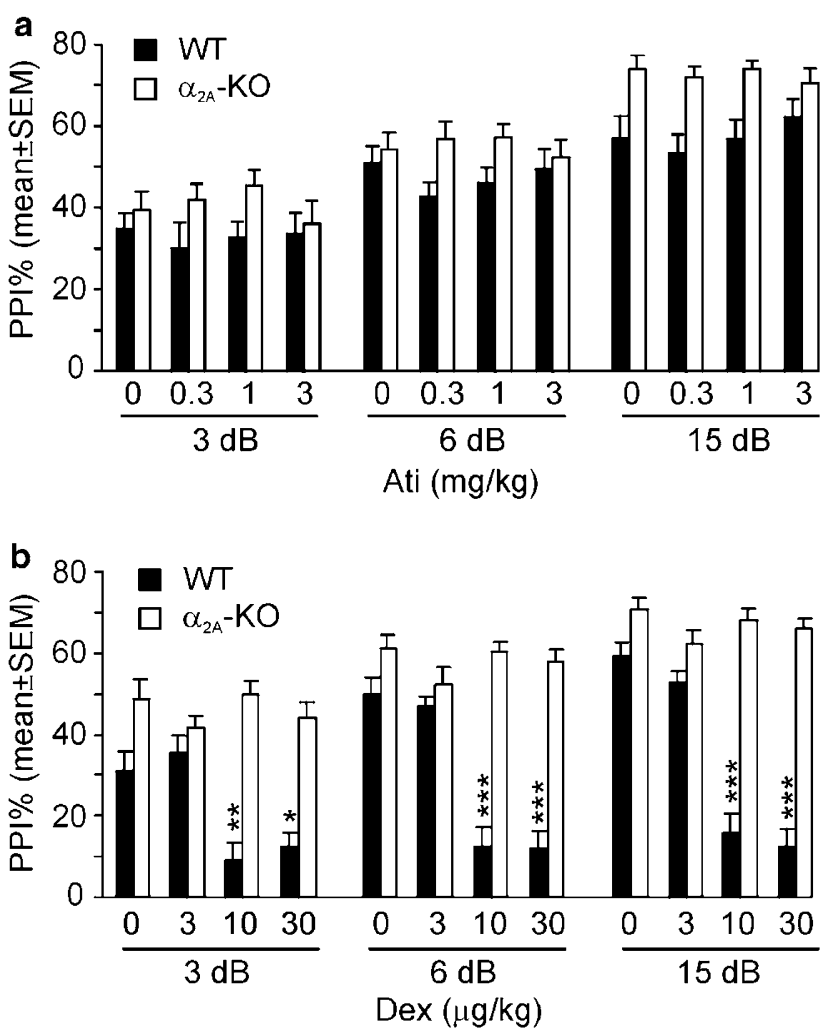

Figure $4 \mathrm{PPI}$ levels of $\alpha_{2 \mathrm{~A}}-\mathrm{KO}$ (open bars) and WT (closed bars) mice (mean \pm SEM, $n=14-15 /$ group) after treatment with atipamezole (a) or dexmedetomidine (b). Atipamezole was ineffective in both genotypes. Dexmedetomidine decreased PPI of WT mice, but the $\alpha_{2 A}-K O$ mice were unaffected $(p<0.00$ I for genotype $x$ dose interaction in two-way ANOVA at all prepulse intensities). ${ }^{*} p<0.05$, ${ }^{*} p p<0.0$ I, $* * * 0<0.00$ I in comparison to vehicle control group. It should be noted that the calculated PPI for 10 and $30 \mu \mathrm{g} / \mathrm{kg}$ Dex groups is questionable, since the drug inhibited startle amplitudes per se.

regions in the levels of $\mathrm{NE}$ and its main metabolite 3methoxy-4-hydroxyphenylglycol (MHPG) in the three-way ANOVA. The effects of D-amph on NE and MHPG were different between the $\alpha_{2 \mathrm{~A}}-\mathrm{KO}$ and WT mice, as NE levels were markedly reduced in all examined brain regions of $\alpha_{2 \mathrm{~A}}-\mathrm{KO}$ mice, but unchanged or only slightly reduced in WT mice, and as MHPG levels were markedly reduced in WT mice, but unchanged or increased in $\alpha_{2 \mathrm{~A}}$-KO mice (Figure 6). The genotype $\times$ amph interaction was statistically significant for NE $(p<0.001)$ in all brain regions, and for MHPG in the cortex $\left(\mathrm{F}_{(1,89)}=24.78, p<0.001\right)$ and thalamushypothalamus $\left(\mathrm{F}_{(1,92)}=4.23, p=0.042\right)$. In the hippocampus, there was also a similar, nonsignificant trend for the genotype $\times$ amph interaction in MHPG $\left(\mathrm{F}_{(1,88)}=2.95\right.$, $p=0.090)$. The reduction in the NE content by $\mathrm{D}$-amph was $43 \%$ in the cortex of $\alpha_{2 \mathrm{~A}}-\mathrm{KO}$ mice, compared to only a $9 \%$ reduction in WT controls (Figure 6a). Conversely, the MHPG content was not influenced by D-amph in $\alpha_{2 \mathrm{~A}}-\mathrm{KO}$ mice $(+6 \%$ in cortex), whereas a $48 \%$ decrease was observed in the cortex of WT mice (Figure 6a).

The D-amph-induced alterations in brain NE metabolism were differently modified in $\alpha_{2 \mathrm{~A}}-\mathrm{KO}$ and WT mice by the $\alpha_{2}$-AR antagonist Ati. The concurrent administration of Ati 

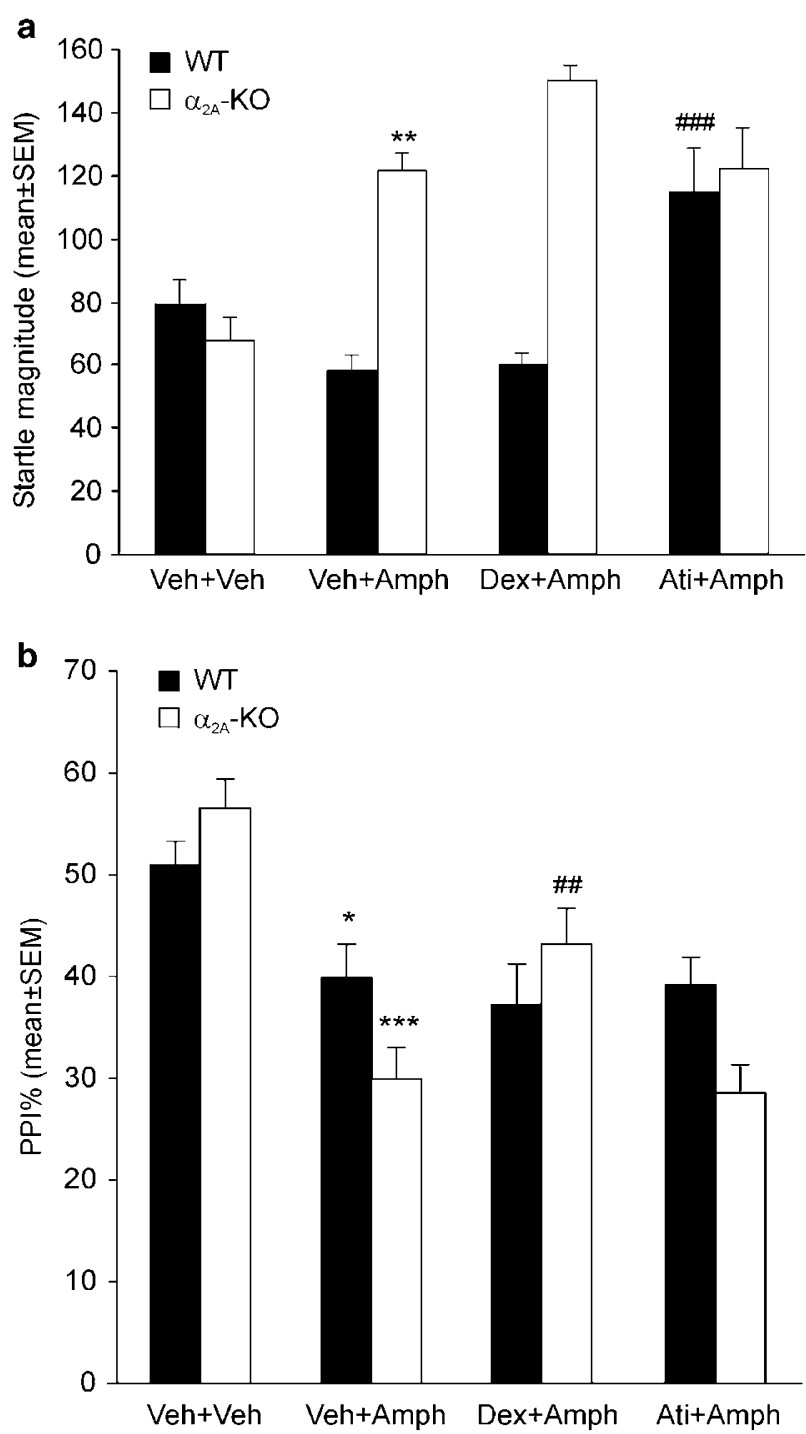

Figure 5 Mean $\pm \operatorname{SEM}(n=|4-| 5 /$ group) startle magnitude (a) and PPI levels (b) of $\alpha_{2 \mathrm{~A}}-\mathrm{KO}$ (open bars) and WT (closed bars) mice. PPI is shown collapsed across prepulse intensities. Treatment groups were as follows: vehicle (Veh + Veh), D-amph $10 \mathrm{mg} / \mathrm{kg}(V e h+A m p h)$, Dex $3 \mu \mathrm{g} / \mathrm{kg}$ and D-amph (Dex + Amph), Ati I mg/kg and D-amph (Ati + Amph). Vehicle, Ati, and Dex were injected $20 \mathrm{~min}$, and D-amph 10 min before the start of the test. D-amph had opposite effects on startle responses in $\alpha_{2 \mathrm{~A}}-\mathrm{KO}$ and $W T$ mice ( $p<0.00$ I; genotype $\times$ amph interaction). Atipamezole increased the D-amph modulated startle responses of WT mice to the level of $\alpha_{2 A^{-}}$ $\mathrm{KO}$ mice after $\mathrm{D}$-amph alone. PPI was more effectively disrupted by D-amph in $\alpha_{2 A}-K O$ mice $(p=0.014$ for genotype $\times$ amph interaction). Dexmedetomidine partly counteracted the D-amph-induced PPI disruption in $\alpha_{2 A}-\mathrm{KO}$ mice, whereas it had no effect in WT control mice. $* p<0.05$, $* * * 0.01$, *** $p<0.00$ I in comparison to vehicle group of the same genotype. $\# p<0.01$, \#\#\# $p<0.001$ in comparison to Veh + Amph group of the same genotype.

$(1 \mathrm{mg} / \mathrm{kg})$ with D-amph produced marked effects in WT, but not in $\alpha_{2 \mathrm{~A}}-\mathrm{KO}$ mice. Consequently, the genotype differences in the responses to D-amph alone in the content of NE and MHPG were abolished after Ati (Figure 6). There was also a tendency for augmentation of the D-amph-induced NE depletion and MHPG increase after administration of Ati to $\alpha_{2 \mathrm{~A}}$-KO mice, but this effect reached statistical significance only for NE in cortex $(p=0.007)$. The $\alpha_{2 \mathrm{~A}}$-AR agonist Dex $(3 \mu \mathrm{g} / \mathrm{kg})$, administered together with $\mathrm{D}$-amph, had no modulatory effects on NE or MHPG responses in any brain region in comparison to the effects of $\mathrm{D}$-amph alone in either genotype (Figure 6).

As reported earlier (Lähdesmäki et al, 2002), the MHPG levels of vehicle-treated $\alpha_{2 \mathrm{~A}}$-KO mice were greater than those of WT controls. The differences were statistically significant in the cortex $(t=3.34 ; p=0.004)$ and the thalamus-hypothalamus $(t=3.68 ; p=0.002)$, and a similar, nonsignificant trend was also seen in the hippocampus (Figure 6).

$D A$, dihydroxyphenylacetic acid (DOPAC) and homovanillic acid (HVA). In response to D-amph, the most prominent changes in DA metabolism were observed in the thalamus and hypothalamus, where the main effect of amph was significant for the parent amine DA $\left(\mathrm{F}_{(1,92)}=67.05\right.$, $p<0.001)$, and for the metabolites DOPAC $\left(\mathrm{F}_{(1,92)}=210.9\right.$, $p<0.001)$ and HVA $\left(\mathrm{F}_{(1,92)}=56.97, p<0.001\right)$. A main effect of genotype was only observed for DOPAC in the cortex $\left(\mathrm{F}_{(1,92)}=6.135, p=0.015\right)$. The $\mathrm{D}$-amph injections had opposing effects on the levels of DA in $\alpha_{2 \mathrm{~A}}-\mathrm{KO}$ and WT mice. In $\alpha_{2 \mathrm{~A}}-\mathrm{KO}$ mice, $\mathrm{D}$-amph tended to increase the brain DA content (except in the thalamus-hypothalamus), whereas slight decreases were noted in all brain regions of WT animals. However, the genotype $\times$ amph interaction for DA was only significant in the striatum $\left(\mathrm{F}_{(1,92)}=5.174\right.$, $p=0.025)$, where $\mathrm{D}$-amph caused a $17 \%$ increase in $\alpha_{2 \mathrm{~A}}-\mathrm{KO}$ mice, compared to a $8 \%$ decrease in $\mathrm{WT}$ mice. For the DA metabolites DOPAC and HVA, a significant genotype $\times$ amph interaction was observed in the striatum for DOPAC $\left(\mathrm{F}_{(1,92)}=5.843, p=0.018\right)$, and in all brain regions for HVA (eg $\mathrm{F}_{(1,87)}=16.81, p<0.001$ in the hippocampus) (Figure 7). The levels of DOPAC were reduced or unaffected by D-amph depending on the brain region, with no major differences observed between the genotypes. The two regions having the highest DA content, the striatum and the thalamus and hypothalamus, were subject to the most marked effects of D-amph. In the striatum, there were $59 \%\left(\alpha_{2 \mathrm{~A}}-\mathrm{KO}\right)$ and $64 \%$ (WT) reductions in DOPAC concentrations in response to D-amph. On the contrary, the levels of HVA were differently changed after D-amph in the $\alpha_{2 \mathrm{~A}}-\mathrm{KO}$ and WT mice (Figure 7; results not shown for DA and DOPAC). In the cortex, hippocampus, and striatum of WT mice, the levels of HVA were unaltered or slightly decreased after D-amph, while statistically significant increases occurred in the cortex, hippocampus, and thalamus-hypothalamus of $\alpha_{2 \mathrm{~A}}-\mathrm{KO}$ mice.

The modulation of $\mathrm{D}$-amph-elicited changes in the metabolism of DA by Dex and Ati was clearly less prominent than the drugs' effects on NE metabolism. Yet, the genotype $\times$ amph $\times$ drug interaction was statistically significant for HVA in the hippocampus $\left(\mathrm{F}_{(2,88)}=3.700\right.$, $p=0.029)$ and in the thalamus and hypothalamus $\left(\mathrm{F}_{(2,92)}=4.927, p=0.009\right) \quad$ (Figure 7). The administration of Dex together with D-amph did not cause additional effects on DA metabolism in $\alpha_{2 \mathrm{~A}}-\mathrm{KO}$ or WT mice, compared to $\mathrm{D}$-amph alone. However, the combination of Ati and D-amph consistently elevated the levels of HVA in WT mice 

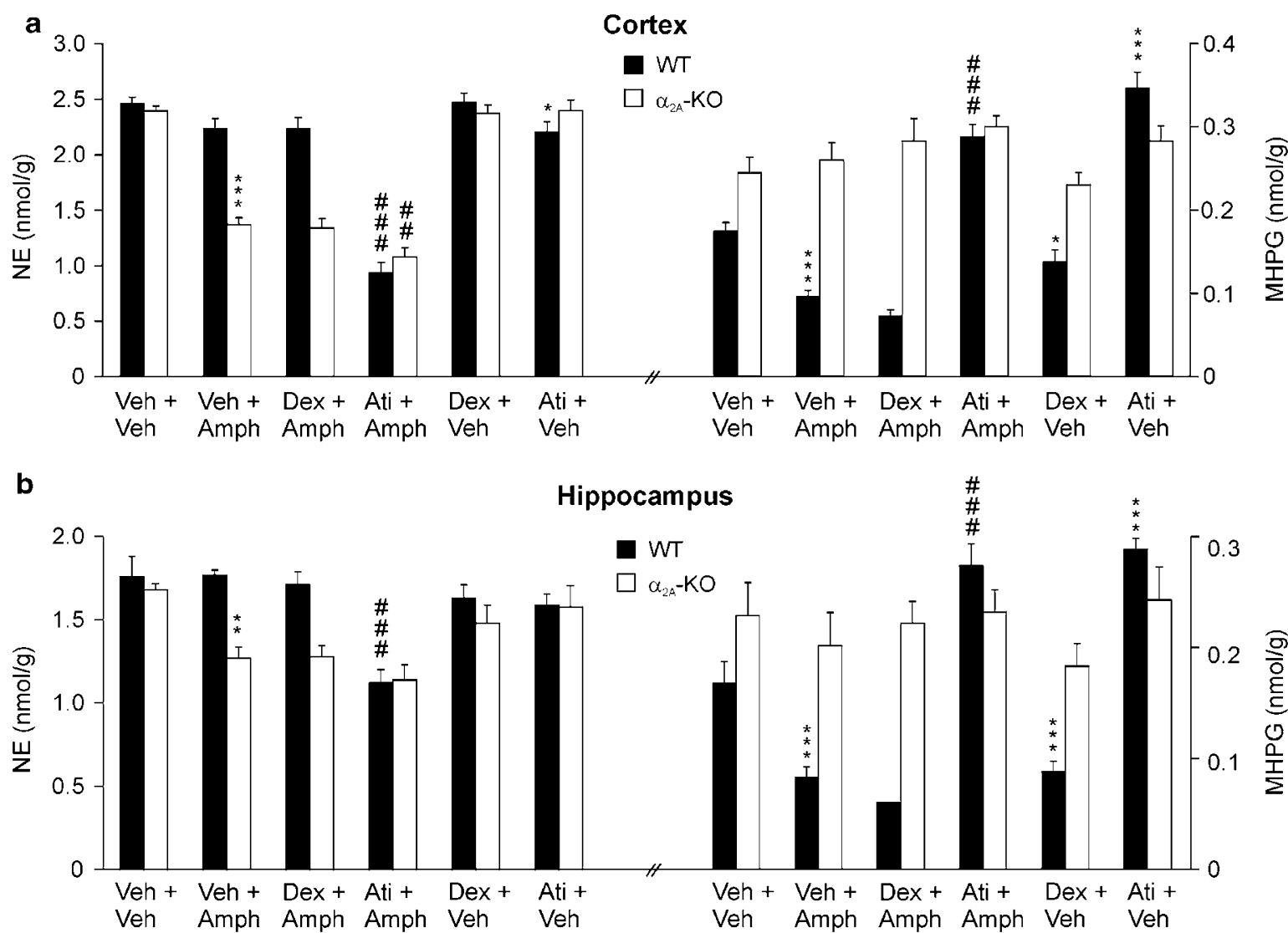

c

Thalamus-hypothalamus

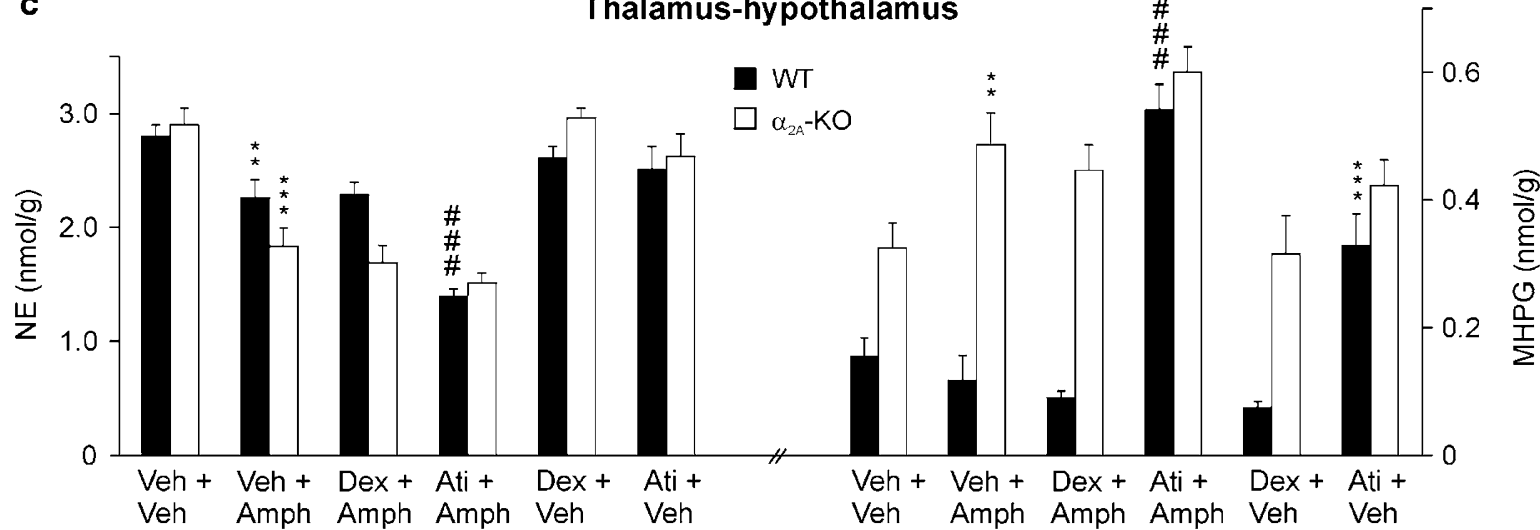

Figure 6 Concentrations of NE and MHPG of $\alpha_{2 A}-K O$ (open bars) and WT (closed bars) mice measured from the cortex (a), hippocampus (b), and thalamus-hypothalamus (c). Treatment groups were vehicle (Veh + Veh), D-amph $10 \mathrm{mg} / \mathrm{kg}(\mathrm{Veh}+\mathrm{Amph})$, Dex $3 \mu \mathrm{g} / \mathrm{kg}$ and D-amph (Dex + Amph), Ati $1 \mathrm{mg} / \mathrm{kg}$ and D-amph (Ati + Amph), Dex $3 \mu \mathrm{g} / \mathrm{kg}$ (Dex + Veh), and Ati I mg/kg (Ati + Veh). Values are nmol/g tissue (mean \pm SEM) ( $n=8-10)$. The first injection was given $50 \mathrm{~min}$ and the second injection 40 min before the mice were killed. In $\alpha_{2 A}-K O$ mice, the NE content of all brain regions was depleted by $\mathrm{D}$-amph, but in WT animals a significant reduction occurred only in the thalamus-hypothalamus. Conversely, MHPG levels of $\alpha_{2 \mathrm{~A}}$-KO mice were unaffected or increased (thalamus-hypothalamus) by D-amph, whereas marked reductions were noted in the cortex and hippocampus of WT mice. $\alpha_{2}$-AR blockade by Ati, administered together with $\mathrm{D}$-amph, abolished the genotype differences seen after D-amph alone. $* * * 0.01$, **** $p<0.00$ I in comparison to vehicle group of the same genotype. ${ }^{\# \#} p<0.01,{ }^{\# \#} p<0.001$ in comparison to Veh + Amph group of the same genotype.

with statistically significant changes noted in the hippocampus ( $+71 \%$ compared to $\mathrm{D}$-amph alone) and the thalamus and hypothalamus $(+28 \%$ compared to D-amph alone) (Figure 7), thus abolishing the genotype differences after D-amph alone. In $\alpha_{2 \mathrm{~A}}$-KO mice, Ati failed to modify the D-amph effects on DA and its metabolites.
TRP, 5-HT, and 5-HIAA. The D-amph injections strongly influenced 5-HT metabolism throughout the brain. In all brain regions, the main effect of amph was significant for the 5-HT precursor TRP, the parent amine 5-HT, and the metabolite 5-hydroxyindoleacetic acid (5-HIAA). The content of TRP was increased more in $\alpha_{2 \mathrm{~A}}$-KO than in WT mice 

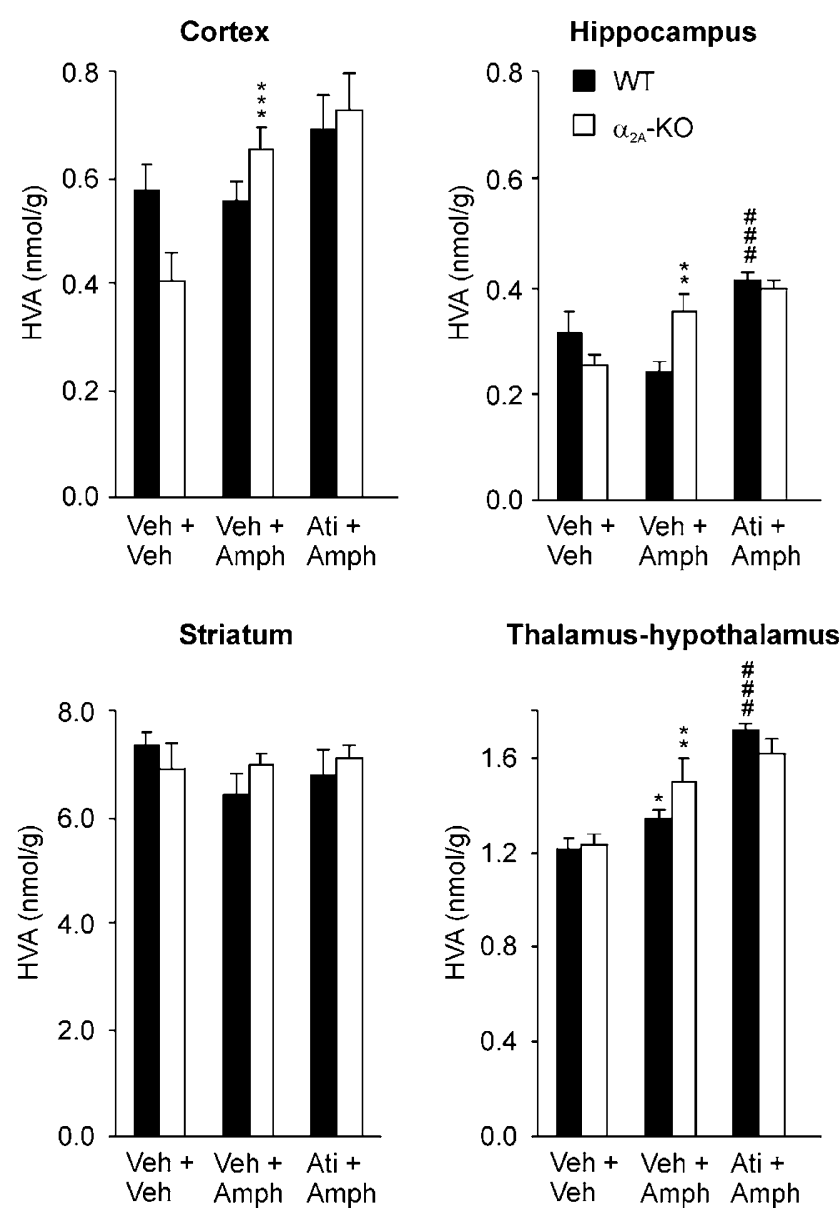

Figure 7 Effects of $D$-amph on the brain concentrations of the DA metabolite HVA in $\alpha_{2 A}-K O$ (open bars) and WT (closed bars) mice (as $\mathrm{nmol} / \mathrm{g}$, mean \pm SEM) $(n=8-10)$. Treatment abbreviations as in Figure 6. HVA levels of $\alpha_{2 A}-K O$ mice were increased by D-amph, but in WT mice only minor changes were observed (genotype $\times$ amph interaction significant in all brain regions, for example, $F_{(1,87)}=|6.81, p<0.00|$ in the hippocampus). Ati abolished the genotype difference by increasing the HVA levels of WT mice. ${ }^{*} p<0.05$, ** $p<0.01$, **** $p<0.001$ in comparison to vehicle group of the same genotype. ${ }^{\# \#} p<0.00$ I in comparison to Veh + Amph group of the same genotype.

by $\mathrm{D}$-amph, that is, there was a significant genotype $\times$ amph interaction in all brain regions $\left(\mathrm{eg}_{(1,88)}=10.68, p=0.002\right.$ in the cortex) (Figure 8). After D-amph, the level of TRP in the cortex of $\alpha_{2 \mathrm{~A}}-\mathrm{KO}$ mice was increased by $90 \%$ compared to a $33 \%$ increase in WT control animals. In both genotypes, $\mathrm{D}$-amph increased the concentrations of 5-HT in the cortex, the hippocampus, and the thalamus-hypothalamus, but had no effect in the striatum. D-amph also similarly decreased the levels of 5-HIAA in both genotypes, with a significant effect of amph observed in each brain region (results not shown). The modulation of $\mathrm{D}$-amph responses by the concomitant administration of Dex or Ati was restricted to a minor increase in the cortical 5-HT content in $\alpha_{2 \mathrm{~A}}-\mathrm{KO}$ mice with Ati (results not shown).

Body temperature. Body temperature before drug administration was similar in $\alpha_{2 \mathrm{~A}}$-KO $\left(39.1 \pm 0.1^{\circ} \mathrm{C}\right.$; mean \pm SEM across all groups) and $\mathrm{WT}\left(39.2 \pm 0.1^{\circ} \mathrm{C}\right)$ mice. In the

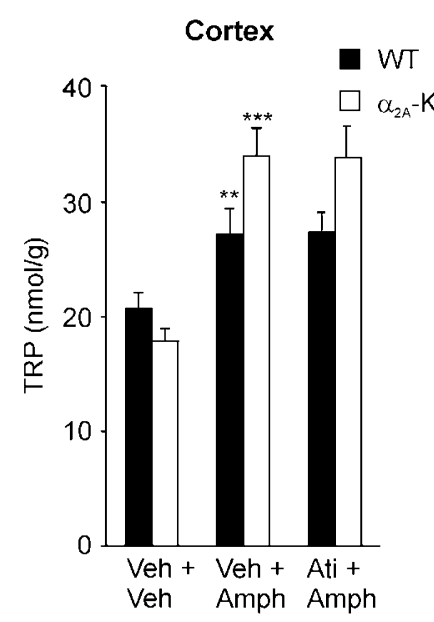

Hippocampus
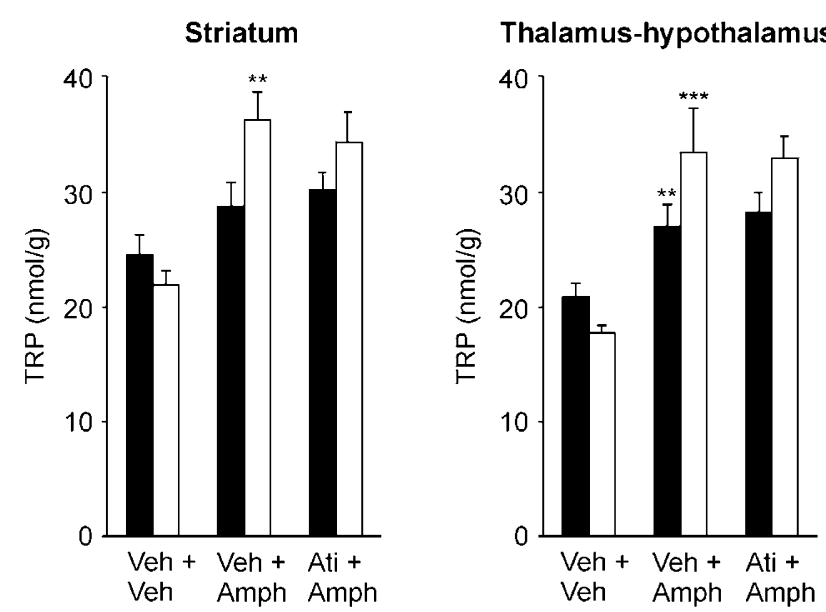

Figure 8 Effects of $d$-amph on the brain concentrations of the 5-HT precursor, TRP in $\alpha_{2 \mathrm{~A}}-\mathrm{KO}$ (open bars) and WT (closed bars) mice (as $n m o l / g$, mean \pm SEM $)(n=8-10)$. Treatment abbreviations as in Figure 6. D-amph increased TRP concentrations more in $\alpha_{2 A}-K O$ mice than in WT controls in all brain regions (eg $F_{(1,88)}=10.68, p=0.002$ for genotype $\times$ amph interaction in cortex). ${ }^{*} p<0.05$, ${ }^{*} * p<0.0$ l, ${ }^{*} * * *<0.00$ I in comparison to vehicle group of the same genotype.

second measurement, prior to decapitation, there was slight reduction in vehicle-treated $\alpha_{2 \mathrm{~A}}-\mathrm{KO}\left(0.5 \pm 0.2^{\circ} \mathrm{C}\right)$ and $\mathrm{WT}$ $\left(0.3 \pm 0.1^{\circ} \mathrm{C}\right)$ mice. Treatment with $\mathrm{D}$-amph slightly increased the body temperature of $\alpha_{2 \mathrm{~A}}-\mathrm{KO}$ mice $\left(+0.6 \pm 0.3^{\circ} \mathrm{C}\right) \quad\left(\mathrm{F}_{(1,46)}=10.02, p=0.003\right)$, but no change $\left(+0.1 \pm 0.3^{\circ} \mathrm{C}\right)\left(\mathrm{F}_{(1,46)}=1.94, p=0.17\right)$ was observed in $\mathrm{WT}$ mice after D-amph.

\section{DISCUSSION}

In these experiments, genetically altered mice and pharmacological manipulations were used to clarify the $\alpha_{2}$-AR subtypes involved in the modulation of the acoustic startle response and its PPI. Additionally, the involvement of the $\alpha_{2 \mathrm{~A}}-\mathrm{AR}$ in the neurochemical and startle-modulating effects of the psychostimulant D-amph was evaluated. The major finding of the current study was that $\alpha_{2 \mathrm{~A}}-\mathrm{KO}$ mice were 
supersensitive to $\mathrm{D}$-amph, revealed as markedly depleted brain NE stores, increased startle amplitudes, and accentuated PPI disruption. The blockade of all $\alpha_{2}$-AR subtypes in WT mice by the subtype-nonselective antagonist atipamezole abolished the D-amph-induced genotype differences in $\mathrm{NE}$ levels and startle responses, confirming the $\alpha_{2}$-AR dependence of these effects.

The formation of MHPG in brains of WT mice was decreased by D-amph, in agreement with an earlier study in mice that suggested that the MHPG reduction resulted primarily from $\mathrm{NE}$ reuptake inhibition by $\mathrm{D}$-amph, and thereby reduced intraneuronal MHPG formation (Heal et al, 1989). The lack of $\alpha_{2 \mathrm{~A}}-\mathrm{AR}$ expression prevented the D-amph-induced MHPG decline. Together, the brain NE and MHPG results suggest that the released NE after D-amph administration normally activates presynaptic $\alpha_{2 \mathrm{~A}^{-}}$ $\mathrm{AR}$ to inhibit further NE release. In the absence of $\alpha_{2 \mathrm{~A}}-\mathrm{AR}$, or during pharmacological blockade of all $\alpha_{2}$-AR subtypes with an antagonist, the NE stores in noradrenergic neurons are susceptible to depletion by $\mathrm{D}$-amph. This corroborates the evidence from $\alpha_{2}$-AR subtype-deficient mice revealing the principal role of the $\alpha_{2 \mathrm{~A}}-\mathrm{AR}$ in regulating the stimulation-induced NE release in cortical and hippocampal slices in vitro (Hein et al, 1999; Trendelenburg et al, 1999, 2001; 2003; Scheibner et al, 2001; Bücheler et al, 2002) and in the prefrontal cortex in vivo (Ihalainen and Tanila, 2002). Furthermore, the observed contribution of the $\alpha_{2}$-ARnoradrenergic system to modulation of the effects of D-amph is in good agreement with two earlier extensive studies on genetically modified mice, reporting increased sensitivity to psychostimulants when the brain NE homeostasis is disturbed, that is, in mice lacking the $\mathrm{NE}$ transporter (Xu et al, 2000) or incapable of synthesizing NE (Weinshenker et al, 2002).

Recent studies on gene-targeted mice have confirmed that non- $\alpha_{2 \mathrm{~A}}-\mathrm{AR}$ subtypes also are involved in the autoreceptor function (for a review, see Philipp et al, 2002). This was also supported by the current study showing that, although statistically significant only in the cortex, D-amph supplementation with Ati tended to cause an additional NE decrease and an MHPG increase in $\alpha_{2 \mathrm{~A}}$-KO mice, too. The regional differences in the effects of $\mathrm{D}$-amph alone were not marked. Yet, the decline in the NE levels of WT mice was restricted to the thalamus-hypothalamus, in accordance with a microdialysis study in rats, which reported an enhanced NE release by D-amph in hypothalamus in comparison to the frontal cortex (Geranton et al, 2003). In addition to the dependence on the brain region, the $\alpha_{2}$-AR modulation of $\mathrm{D}$-amph-induced NE responses has also been shown to depend on the dose used. Low doses of D-amph have been proposed to elevate extracellular NE mainly by inhibiting its reuptake; this impulse-flow-dependent effect is modulated by presynaptic $\alpha_{2}$-autoreceptors (Florin et al, 1994; Geranton et al, 2003). On the contrary, the NE release after high doses of $\mathrm{D}$-amph, suggested to be mediated by an impulse-flow-independent mechanism, was not significantly modulated by the administration of an $\alpha_{2}$-AR agonist or antagonist (Florin et al, 1994; Geranton et al, 2003). In our study, however, regardless of the high $\mathrm{D}$-amph dose employed, lack of $\alpha_{2 A}$-AR expression or blockade of $\alpha_{2}$ ARs in WT mice with Ati resulted in more efficient depletion of NE stores by D-amph. These results suggest that, at least in mice, the lack or pharmacological blockade of inhibitory $\alpha_{2 \mathrm{~A}}$-ARs is able to significantly augment the $\mathrm{NE}$ response also to a high dose of D-amph. On the contrary, activation of $\alpha_{2}$-ARs with Dex did not affect the D-amphinduced NE or MHPG changes, probably because of the already maximal activation of the inhibitory $\alpha_{2}$-AR subtype(s) by endogenous NE.

As expected, D-amph had marked effects also on the metabolism of DA, but, compared to its effects on NE, the $\alpha_{2 \mathrm{~A}}-\mathrm{KO}$ and control mice did not show such clear-cut differences. The concentration of DA was reduced by $\mathrm{D}$-amph in the thalamus-hypothalamus (by $18 \%$ in $\alpha_{2 \mathrm{~A}^{-}}$ $\mathrm{KO}$ and by $22 \%$ in WT mice). DOPAC was decreased similarly in both genotypes. Yet, the effects of $D$-amph on HVA differed in all brain regions between the genotypes, with increases in $\alpha_{2 \mathrm{~A}}-\mathrm{KO}$ mice, in contrast to only minor effects in WT mice. Considering the importance of noradrenergic transmission in regulating the DA-related neurochemical and behavioral effects of psychostimulants (Pan et al, 1996; Darracq et al, 1998; Drouin et al, 2002; Ventura et al, 2003), and the disturbed basal NE metabolism in the brains of $\alpha_{2 \mathrm{~A}}$-KO mice (Lähdesmäki et al, 2002), the increased HVA formation in D-amph-treated $\alpha_{2 \mathrm{~A}}-\mathrm{KO}$ mice was not surprising. Decreased DOPAC levels after D-amph administration, observed in both genotypes, corroborate results in rats from regions representing dopaminergic projection areas (Kuczenski, 1980; Nicolaou, 1980; Elverfors and Nissbrandt, 1992; Karoum et al, 1994). The decreased DOPAC formation, reflecting reduced intraneuronal metabolism of DA resulting from reuptake blockade of DA by Damph, thus, is not affected by $\alpha_{2 \mathrm{~A}}-\mathrm{AR}$. On the contrary, the formation of HVA occurs mainly extracellularly, and the elevated HVA concentrations of $\alpha_{2 \mathrm{~A}}$-KO mice may therefore represent increased DA release in the absence of $\alpha_{2 A}-A R$ heteroreceptor-mediated inhibition (Bücheler et al, 2002). Supporting this view, the HVA levels of WT mice after combined Ati-D-amph treatment were elevated to the level observed in $\alpha_{2 \mathrm{~A}}$-KO mice after D-amph alone, except in the striatum, where the $\alpha_{2 \mathrm{C}}-\mathrm{AR}$ subtype predominates.

$\mathrm{D}$-amph increased the concentrations of the 5-HT precursor, TRP. In $\alpha_{2 \mathrm{~A}}-\mathrm{KO}$ mice, the TRP increase by D-amph was augmented throughout the brain (eg a $90 \%$ increase in cortex compared to a $33 \%$ increase in WT animals). Recently, pharmacological activation of both $\beta_{2}$ - and $\beta_{3}$-adrenergic receptors was reported to markedly increase brain TRP levels (Lenard et al, 2003). Lack of sympathetic inhibition in $\alpha_{2 \mathrm{~A}}$-KO mice (Brede et al, 2002) after stimulation with $\mathrm{D}$-amph, leading to enhanced $\beta$-adrenergic activation, probably explains this TRP difference. Independent of the genotype and the brain region, D-amph increased 5-HT and decreased 5-HIAA levels.

Baseline startle reactivity, in the absence of injections, was similar in $\alpha_{2 \mathrm{~A}}$-KO and WT mice. The first vehicle injections significantly increased the startle responses of $\alpha_{2 \mathrm{~A}}$-KO mice compared to baseline, but WT mice were not similarly influenced. The increased startle of $\alpha_{2 \mathrm{~A}}$-KO mice after the first injections may be attributed to elevated stress caused by the injections and/or the somewhat aversive test situation, in agreement with the increased sensitivity to injections previously reported in $\alpha_{2 \mathrm{~A}}-\mathrm{KO}$ mice in the openfield test and the light-dark paradigm (Schramm et al, 2001). Moreover, the neurobehavioral phenotype of $\alpha_{2 \mathrm{~A}}-\mathrm{KO}$ 
mice is characterized by increased anxiety-related behaviors (Lähdesmäki et al, 2002). Increased startle has been consistently reported after the $\alpha_{2}$-AR antagonists yohimbine, idazoxan, and RS-79948-197 in rats (White and Birkle, 2001), and after yohimbine in humans (Morgan et al, 1993, 1995). Interestingly, Ati had opposite effects on startle in $\alpha_{2 \mathrm{~A}}-\mathrm{KO}$ and WT mice, indicating that blockade of $\alpha_{2 \mathrm{~A}}-\mathrm{AR}$ mediates the startle-enhancing, anxiogenic-like effects of $\alpha_{2}$ AR antagonists. Considering the altered startle reflex and cortical arousal in mice lacking the $\alpha_{2 \mathrm{C}}$-AR (Sallinen et al, 1998; Puoliväli et al, 2002), it is possible that the slight startle reduction by Ati in $\alpha_{2 \mathrm{~A}}-\mathrm{KO}$ mice is based on $\alpha_{2 \mathrm{C}}-\mathrm{AR}$ blockade.

Dex decreased startle dose-dependently in WT mice, whereas the $\alpha_{2 \mathrm{~A}}-\mathrm{KO}$ animals were unaffected. Earlier studies have shown that the $\alpha_{2}$-AR agonist clonidine decreases startle after systemic administration in humans (Kumari et al, 1996) and rats (Davis et al, 1977), and after spinal (Davis and Astrachan, 1981) or intra-amygdaloid (Schulz et al, 2002) administration in rats. The almost totally abolished startle reflex of WT mice after Dex 10 and especially $30 \mu \mathrm{g} / \mathrm{kg}$ was likely due to its sedative effect. The sedation elicited by $\alpha_{2}$-AR agonists is mainly mediated through activation of $\alpha_{2 \mathrm{~A}}-\mathrm{AR}$, and has previously been shown to be attenuated, but not totally absent in mice lacking functional $\alpha_{2 \mathrm{~A}}$-AR (Hunter et al, 1997; Lakhlani et al, 1997; Lähdesmäki et al, 2003). The smallest Dex dose, $3 \mu \mathrm{g} /$ $\mathrm{kg}$, is not, however, sedative in mice (Hunter et al, 1997), but still effectively reduced startle in WT mice. This suggests that the $\alpha_{2}$-AR agonist-mediated startle attenuation is also $\alpha_{2 \mathrm{~A}}-\mathrm{AR}$ dependent.

Consistent with the accentuated D-amph response in brain NE metabolism, increased sensitivity of $\alpha_{2 \mathrm{~A}}$-KO mice to the effects of D-amph was also observed in startle reactivity. In WT mice, D-amph mildly (statistically nonsignificantly) decreased startle amplitudes, as reported earlier in C57Bl/6 mice (Ralph et al, 2001; Varty et al, 2001 ). It seems evident that the $80 \%$ increase of startle in $\alpha_{2 \mathrm{~A}}-\mathrm{KO}$ mice induced by $\mathrm{D}$-amph was, indeed, due to the lack of $\alpha_{2 \mathrm{~A}}$-AR expression, since the startle responses of WT mice after supplementation with Ati were increased to the level of $\alpha_{2 \mathrm{~A}}-\mathrm{KO}$ mice treated with $\mathrm{D}$-amph alone. This suggests that the synaptic NE, increased after D-amph administration, activates $\alpha_{2 \mathrm{~A}}-\mathrm{AR}$ in WT mice, thereby inhibiting further NE release and also preventing the startle enhancement.

The PPI levels of $\alpha_{2 \mathrm{~A}}-\mathrm{KO}$ mice were slightly elevated compared to WT mice in control groups of all experiments, regardless of whether the control groups were (experiments 2,3 and 4) or were not (experiment 1) given vehicle injections. Recently, several genetically altered mouse lines with modified expression of neurotransmitter receptors or transporters have been examined to investigate the potential genetic basis of sensorimotor gating (Geyer et al, 2002). Mouse strains reported to have increased basal PPI have included $5 \mathrm{HT}_{1 \mathrm{~B}}-\mathrm{KO}$ (Dulawa et al, 2000) and $\alpha_{2 \mathrm{C}}$-overexpressing mice (Sallinen et al, 1998). It can be speculated that endogenous NE tonically reduces the level of PPI via $\alpha_{2 \mathrm{~A}}-\mathrm{AR}$, and inactivation of the $\alpha_{2 \mathrm{~A}}-\mathrm{AR}$ gene thus results in increased PPI. However, in spite of the baseline PPI difference between the genotypes, no significant modulation of PPI was observed after Ati or nonsedative doses of Dex.
In line with the neurochemistry and startle results, D-amph again had more pronounced effects on PPI in $\alpha_{2 \mathrm{~A}}$-KO mice. D-amph caused clear PPI disruption across all prepulse intensities in $\alpha_{2 \mathrm{~A}}-\mathrm{KO}$ mice, compared to a less clear-cut decrease in WT mice only at the $3 \mathrm{~dB}$ intensity (data not shown for individual prepulse intensity levels). The PPI disruption in $\alpha_{2 \mathrm{~A}}$-KO mice was also partly opposed by Dex, suggesting that other $\alpha_{2}$-AR subtypes, possibly $\alpha_{2 \mathrm{C}}$-AR (Sallinen et al, 1998), modulate PPI during D-amph challenge.

The current results show that the perturbation in brain $\mathrm{NE}$ homeostasis of $\alpha_{2 \mathrm{~A}}-\mathrm{KO}$ mice is drastically enhanced when the mice are challenged with $D$-amph. The supersensitivity of $\alpha_{2 \mathrm{~A}}-\mathrm{KO}$ mice to the behavioral and neurochemical effects of $\mathrm{D}$-amph indicates a crucial involvement of $\alpha_{2 \mathrm{~A}}$-AR in the modulation of the actions of the psychostimulant. It is possible that the therapeutic effects of D-amph in ADHD, as well as the stimulant effects of abused D-amph, are significantly regulated by brain $\alpha_{2}$-ARs. In the absence of the inhibitory control normally attributable to $\alpha_{2 \mathrm{~A}}-\mathrm{AR}, \mathrm{D}-\mathrm{amph}$ administration results in increased startle reactivity and more pronounced impairment of sensorimotor gating, which are probably caused by concomitant changes in either NE or DA release. These results provide evidence for participation of $\alpha_{2 \mathrm{~A}}$-AR in neurobiological processes related to disturbed attentional regulation or impaired sensorimotor information processing, such as ADHD or schizophrenia. The results also suggest that a potentially harmful drug interaction may exist between amphetamine-like psychostimulants and $\alpha_{2}$-AR antagonists.

\section{ACKNOWLEDGEMENTS}

Brian Kobilka and John Altman are acknowledged for providing the $\alpha_{2 \mathrm{~A}}-\mathrm{KO}$ mice. The expertise of Lauri Sillanmäki in statistical analyses is also acknowledged. In addition, the help of Veronica Fagerholm has been invaluable. The work was supported by the Academy of Finland and Orion Corporation.

\section{REFERENCES}

Altman JD, Trendelenburg AU, MacMillan L, Bernstein D, Limbird L, Starke K et al (1999). Abnormal regulation of the sympathetic nervous system in alpha2A-adrenergic receptor knockout mice. Mol Pharmacol 56: 154-161.

Arnold LE, Huestis RD, Smeltzer DJ, Scheib J, Wemmer D, Colner G (1976). Levoamphetamine $v s$ dextroamphetamine in minimal brain dysfunction. Replication, time response, and differential effect by diagnostic group and family rating. Arch Gen Psychiatry 33: 292-301.

Braff DL, Geyer MA, Swerdlow NR (2001). Human studies of prepulse inhibition of startle: normal subjects, patient groups, and pharmacological studies. Psychopharmacology (Berl) 156: 234-258.

Brede M, Wiesmann F, Jahns R, Hadamek K, Arnolt C, Neubauer S et al (2002). Feedback inhibition of catecholamine release by two different alpha2-adrenoceptor subtypes prevents progression of heart failure. Circulation 106: 2491-2496.

Bücheler MM, Hadamek K, Hein L (2002). Two alpha(2)adrenergic receptor subtypes, alpha(2A) and alpha(2C), inhibit 
transmitter release in the brain of gene-targeted mice. $\mathrm{Neu}$ roscience 109: 819-826.

Darracq L, Blanc G, Glowinski J, Tassin JP (1998). Importance of the noradrenaline-dopamine coupling in the locomotor activating effects of D-amphetamine. J Neurosci 18: 2729-2739.

Davis M, Astrachan DI (1981). Spinal modulation of acoustic startle: opposite effects of clonidine and D-amphetamine. Psychopharmacology (Berl) 75: 219-225.

Davis M, Cedarbaum JM, Aghajanian GK, Gendelman DS (1977). Effects of clonidine on habituation and sensitization of acoustic startle in normal, decerebrate and locus coeruleus lesioned rats. Psychopharmacology (Berl) 51: 243-253.

Drouin C, Darracq L, Trovero F, Blanc G, Glowinski J, Cotecchia S et al (2002). Alpha1b-adrenergic receptors control locomotor and rewarding effects of psychostimulants and opiates. J Neurosci 22: 2873-2884.

Dulawa SC, Gross C, Stark KL, Hen R, Geyer MA (2000). Knockout mice reveal opposite roles for serotonin $1 \mathrm{~A}$ and $1 \mathrm{~B}$ receptors in prepulse inhibition. Neuropsychopharmacology 22: 650-659.

Elverfors A, Nissbrandt H (1992). Effects of D-amphetamine on dopaminergic neurotransmission; a comparison between the substantia nigra and the striatum. Neuropharmacology 31: 661-670.

Florin SM, Kuczenski R, Segal DS (1994). Regional extracellular norepinephrine responses to amphetamine and cocaine and effects of clonidine pretreatment. Brain Res 654: 53-62.

Franowicz JS, Kessler LE, Borja CM, Kobilka BK, Limbird LE, Arnsten AF (2002). Mutation of the alpha2A-adrenoceptor impairs working memory performance and annuls cognitive enhancement by guanfacine. J Neurosci 22: 8771-8777.

Geranton SM, Heal DJ, Stanford SC (2003). Differences in the mechanisms that increase noradrenaline efflux after administration of D-amphetamine: a dual-probe microdialysis study in rat frontal cortex and hypothalamus. Br J Pharmacol 139: 14411448.

Geyer MA, McIlwain KL, Paylor R (2002). Mouse genetic models for prepulse inhibition: an early review. Mol Psychiatry 7: 10391053.

Hawk Jr LW, Yartz AR, Pelham Jr WE, Lock TM (2003). The effects of methylphenidate on prepulse inhibition during attended and ignored prestimuli among boys with attentiondeficit hyperactivity disorder. Psychopharmacology (Berl) 165 118-127.

Heal DJ, Prow MR, Buckett WR (1989). Measurement of 3methoxy-4-hydroxyphenylglycol (MHPG) in mouse brain by h.p.l.c. with electrochemical detection, as an index of noradrenaline utilisation and presynaptic alpha 2 -adrenoceptor function. Br J Pharmacol 96: 547-556.

Hein L, Altman JD, Kobilka BK (1999). Two functionally distinct alpha2-adrenergic receptors regulate sympathetic neurotransmission. Nature 402: 181-184.

Hunter JC, Fontana DJ, Hedley LR, Jasper JR, Lewis R, Link RE et al (1997). Assessment of the role of alpha2-adrenoceptor subtypes in the antinociceptive, sedative and hypothermic action of dexmedetomidine in transgenic mice. Br J Pharmacol 122: 13391344.

Ihalainen JA, Tanila $\mathrm{H}$ (2002). In vivo regulation of dopamine and noradrenaline release by alpha2A-adrenoceptors in the mouse prefrontal cortex. Eur J Neurosci 15: 1789-1794.

Karoum F, Chrapusta SJ, Brinjak R, Hitri A, Wyatt RJ (1994). Regional effects of amphetamine, cocaine, nomifensine and GBR 12909 on the dynamics of dopamine release and metabolism in the rat brain. Br J Pharmacol 113: 1391-1399.

Koch M (1999). The neurobiology of startle. Prog Neurobiol 59: 107-128.

Kuczenski R (1980). Amphetamine-haloperidol interactions on striatal and mesolimbic tyrosine hydroxylase activity and dopamine metabolism. J Pharmacol Exp Ther 215: 135-142.
Kumari V, Cotter P, Corr PJ, Gray JA, Checkley SA (1996). Effect of clonidine on the human acoustic startle reflex. Psychopharmacology 123: 353-360.

Lähdesmäki J, Sallinen J, MacDonald E, Kobilka BK, Fagerholm V, Scheinin M (2002). Behavioral and neurochemical characterization of alpha2A-adrenergic receptor knockout mice. Neuroscience 113: 289-299.

Lähdesmäki J, Sallinen J, MacDonald E, Sirviö J, Scheinin M (2003). Alpha2-adrenergic drug effects on brain monoamines, locomotion, and body temperature are largely abolished in mice lacking the alpha2A-adrenoceptor subtype. Neuropharmacology 44: 882-892.

Lakhlani PP, MacMillan LB, Guo TZ, McCool BA, Lovinger DM, Maze $M$ et al (1997). Substitution of a mutant alpha2aadrenergic receptor via 'hit and run' gene targeting reveals the role of this subtype in sedative, analgesic, and anestheticsparing responses in vivo. Proc Natl Acad Sci USA 94: 9950-9955.

Lenard NR, Gettys TW, Dunn AJ (2003). Activation of beta 2- and beta 3-adrenergic receptors increases brain tryptophan. J Pharmacol Exp Ther 305: 653-659.

MacDonald E, Scheinin H, Scheinin M (1988). Behavioural and neurochemical effects of medetomidine, a novel veterinary sedative. Eur J Pharmacol 158: 119-127.

Mansbach RS, Geyer MA, Braff DL (1988). Dopaminergic stimulation disrupts sensorimotor gating in the rat. Psychopharmacology (Berl) 94: 507-514.

Mefford I (1981). Applications of high performance liquid chromatography with electrochemical detection to neurochemical analysis: Measurement of catecholamines, serotonin and metabolites in rat brain. J Neurosci Methods 3: 207-224.

Morgan CA, Southwick SM, Grillon C, Davis M, Krystal JH, Charney DS (1993). Yohimbine-facilitated acoustic startle reflex in humans. Psychopharmacology 110: 342-346.

Morgan CA, Grillon C, Southwick SM, Nagy LM, Davis M, Krystal $\mathrm{JH}$ et al (1995). Yohimbine facilitated acoustic startle in combat veterans with post-traumatic stress disorder. Psychopharmacology (Berl) 117: 466-471.

Nicolaou NM (1980). Acute and chronic effects of neuroleptics and acute effects of apomorphine and amphetamine on dopamine turnover in corpus striatum and substantia nigra of the rat brain. Eur J Pharmacol 64: 123-132.

Pan WH, Sung JC, Fuh SM (1996). Locally application of amphetamine into the ventral tegmental area enhances dopamine release in the nucleus accumbens and the medial prefrontal cortex through noradrenergic neurotransmission. J Pharmacol Exp Ther 278: 725-731.

Philipp M, Brede M, Hein L (2002). Physiological significance of alpha(2)-adrenergic receptor subtype diversity: one receptor is not enough. Am J Physiol Regul Integr Comp Physiol 283: 287-295.

Puoliväli J, Björklund M, Holmberg M, Ihalainen JA, Scheinin M, Tanila H (2002). Alpha2C-adrenoceptor mediated regulation of cortical EEG arousal. Neuropharmacology 43: 1305-1312.

Ralph RJ, Paulus MP, Geyer MA (2001). Strain-specific effects of amphetamine on prepulse inhibition and patterns of locomotor behavior in mice. J Pharmacol Exp Ther 298: 148-155.

Sallinen J, Haapalinna A, Viitamaa T, Kobilka BK, Scheinin M (1998). Adrenergic $\alpha 2$ C-receptors modulate the acoustic startle reflex, prepulse inhibition, and aggression in mice. J Neurosci 18 3035-3042.

Scheibner J, Trendelenburg A, Hein L, Starke K (2001). Alpha(2)adrenoceptors modulating neuronal serotonin release: a study in alpha(2)-adrenoceptor subtype-deficient mice. $\mathrm{Br} J$ Pharmacol 132: 925-933.

Schramm NL, McDonald MP, Limbird LE (2001). The alpha(2a)adrenergic receptor plays a protective role in mouse behavioral models of depression and anxiety. J Neurosci 21: 4875-4882. 
Schulz B, Fendt M, Schnitzler HU (2002). Clonidine injections into the lateral nucleus of the amygdala block acquisition and expression of fear-potentiated startle. Eur J Neurosci 15: 151-157.

Segal DS, Kuczenski R (1994). Behavioral pharmacology of amphetamine. In: Cho AK, Segal DS (eds) Amphetamine and its Analogs: Psychopharmacology, Toxicology and Abuse. Academic Press Inc: Orlando. pp 115-150.

Spencer T, Biederman J, Wilens T, Harding M, O'Donnell D, Griffin S (1996). Pharmacotherapy of attention-deficit hyperactivity disorder across the life cycle. J Am Acad Child Adolesc Psychiatry 35: 409-432.

Starke K (2001). Presynaptic autoreceptors in the third decade: focus on alpha2-adrenoceptors. J Neurochem 78: 685-693.

Swerdlow NR, Braff DL, Geyer MA (2000). Animal models of deficient sensorimotor gating: what we know, what we think we know, and what we hope to know soon. Behav Pharmacol 11: 185-204.

Trendelenburg AU, Hein L, Gaiser EG, Starke K (1999). Occurrence, pharmacology and function of presynaptic alpha2autoreceptors in alpha2A/D-adrenoceptor-deficient mice. Naunyn-Schmiedeberg's Arch Pharmacol 360: 540-551.

Trendelenburg AU, Klebroff W, Hein L, Starke K (2001). A study of presynaptic alpha2-autoreceptors in alpha2A/D-, alpha2B- and alpha2C-adrenoceptor-deficient mice. Naunyn-Schmiedeberg's Arch Pharmacol 364: 117-130.

Trendelenburg AU, Philipp M, Meyer A, Klebroff W, Hein L, Starke K (2003). All three alpha(2)-adrenoceptor types serve as autoreceptors in postganglionic sympathetic neurons. NaunynSchmiedeberg's Arch Pharmacol 368: 504-512.

Ujike H (2002). Stimulant-induced psychosis and schizophrenia: the role of sensitization. Curr Psychiatry Rep 4: 177-184.
Varty GB, Walters N, Cohen-Williams M, Carey GJ (2001). Comparison of apomorphine, amphetamine and dizocilpine disruptions of prepulse inhibition in inbred and outbred mice strains. Eur J Pharmacol 424: 27-36.

Weinshenker D, Miller NS, Blizinsky K, Laughlin ML, Palmiter RD (2002). Mice with chronic norepinephrine deficiency resemble amphetamine-sensitized animals. Proc Natl Acad Sci USA 99: 13873-13877.

Ventura R, Cabib S, Alcaro A, Orsini C, Puglisi-Allegra S (2003). Norepinephrine in the prefrontal cortex is critical for amphetamine-induced reward and mesoaccumbens dopamine release. J Neurosci 23: 1879-1885.

White DA, Birkle DL (2001). The differential effects of prenatal stress in rats on the acoustic startle reflex under baseline conditions and in response to anxiogenic drugs. Psychopharmacology (Berl) 154: 169-176.

Wilens TE, Biederman J, Spencer TJ, Prince J (1995). Pharmacotherapy of adult attention deficit/hyperactivity disorder: a review. J Clin Psychopharmacol 15: 270-279.

Wise RA (1996). Addictive drugs and brain stimulation reward. Annu Rev Neurosci 19: 319-340.

Wortley KE, Hughes ZA, Heal DJ, Stanford SC (1999). Comparison of changes in the extracellular concentration of noradrenaline in rat frontal cortex induced by sibutramine or D-amphetamine: modulation by alpha2-adrenoceptors. Br J Pharmacol 127: 1860-1866.

Xu F, Gainetdinov RR, Wetsel WC, Jones SR, Bohn LM, Miller GW et al (2000). Mice lacking the norepinephrine transporter are supersensitive to psychostimulants. Nat Neurosci 3: 465-471.

Yavich L, Lappalainen R, Sirviö J, Haapalinna A, MacDonald E (1997). Alpha2-adrenergic control of dopamine overflow and metabolism in mouse striatum. Eur J Pharmacol 339: 113-119. 